\title{
Sequestration of Brilliant Green Dye by Coriander Leaf: Isotherm and Kinetic Studies
}

\author{
Hemanta Mukherjee and Soma Mukherjee* \\ Department of Environmental Science, University of Kalyani, West Bengal 741235, India
}

('Corresponding author's e-mail: somam580@gmail.com)

Received: 3 April 2021, Revised: 14 June 2021, Accepted: 23 June 2021

\begin{abstract}
Adsorption process has been performed to investigate the potentiality of coriander leaf to sequester brilliant green (BG) dye from the aqueous phase. Coriander leaf of 75-micron size has been characterized by SEM, BET, FTIR etc. In the present study, emphasis has been given on the removal of BG dye under different conditions viz. dose of biomaterial $(10.0-100.0 \mathrm{mg}), \mathrm{pH}(2.0-12.0)$ and dye concentration $(10.0-100.0 \mathrm{mg} / \mathrm{L})$ by Taguchi optimization. The batch experiments have been conducted at $25^{\circ} \mathrm{C}$ with stirring speed of $120.0 \mathrm{rpm}$. The kinetic study is performed at two different temperatures, 30 and $40{ }^{\circ} \mathrm{C}$. The batch adsorption process for sequestration of the dye followed pseudo- $2^{\text {nd }}$ order kinetics $\left(\mathrm{R}^{2}=0.99\right)$. The study also reveals that the Freundlich isotherm is the best fitted $\left(\mathrm{R}^{2}=0.96\right)$ model. The adsorption capacity is $68.49 \mathrm{mg} / \mathrm{g}$ and the overall removal efficiency is above $80.0 \%$.
\end{abstract}

Keywords: Adsorption, Coriander, Pseudo- $2^{\text {nd }}$ order, Isotherm, Taguchi optimization

\section{Introduction}

Sequestration of dyes and pigments from the polluted water is an objective of immense importance in a diversified environmental field. Dyes and their intermediates $\left(7 \times 10^{5}\right.$ ton per annum) used in various industries generate large amount of wastewater, and thereby causes environmental pollution [1-3]. Brilliant green (BG) belongs to triarylmethane dyes and widely used in various sectors viz. textile, pharmaceutical, ink and paint industries etc. [4,5]. In spite of its lot of applications, it causes irritation to the gastrointestinal tract, nausea, vomiting and diarrhea in human depending on the exposure time and concentration [6]. Therefore, the sequestration of such coloring agent is necessary.

Several treatment methods viz. biological treatment, coagulation, nano-filtration, ozonation, photo degradation and adsorption are often applied for the removal of dyes [7]. Among processes used to sequestrate dyes from the aqueous phase, adsorption using biomass, is much more convenient due to high efficiency, easy availability, low-cost, renewable and less sensitivity towards toxic substances [8]. Thus, considerable attention should be placed to explore different types of waste biomass as suitable adsorbents for removal of dyes and pigments in view of environmental sustainability as well as economical feasibility.

Coriander (Coriander sativum) is an annual herb and cultivated in almost all countries throughout the year. Seeds are used in food flavoring industries (bakery and confectionary) and leaves are used as ingredient in food dishes. Coriander (leaf, root and seed) has also some medicinal values due to presence of polyphenols, coriandrol, monoterpene hydrocarbons, heterocyclic compounds, isocoumacin, phthalides, phenolic acids, sterols etc. [9]. Leaves contain vitamin A, B (riboflavin), C and dietary fiber. Nadeem et al. [10] analysed the protein, fat, starch, vitamin, mineral contents of fresh leaves of coriander.

It is revealed from the literature that several research works have been carried out on coriander seeds and its waste for the effective removal of heavy metals $\left(\mathrm{Cu}^{+2}, \mathrm{Zn}^{+2}, \mathrm{~Pb}^{+2}, \mathrm{Hg}^{+2}, \mathrm{CH}_{3} \mathrm{Hg}^{+}\right)[11,12]$ and dyes [13]. Nutraceutical industrials coriander seed spent has adsorption potentiality for removing of acid black 52, congo red, methylene blue, ethidium bromide and acid blue 113 [13 and references therein]. Few research works have been conducted to understand the potentiality of coriander leaf to remove environmental pollutants. The above objective has been realised in the present work via the use of easily available, low-cost and non-toxic coriander leaf as an adsorbent for the effective removal of Brilliant green dye under the influence of different parameters along with Taguchi optimization. Isotherm, kinetics and thermodynamic studies have also been performed to explore the insight of adsorption 
behaviour. This study might be helpful for the valorisation of biomass derived from the coriander as an adsorbent for the remediation of dye contaminated effluent.

\section{Materials and methods}

\section{Biomass and dye}

Coriander leaves have been collected from the local market of Tribeni, West Bengal. It is washed with tap water, dilute acid and base $(0.1(\mathrm{~N}) \mathrm{HCl}$ and $0.1(\mathrm{~N}) \mathrm{NaOH})$, distilled water to obtain the neutral $\mathrm{pH}$. The leaves are dried at $105^{\circ} \mathrm{C}$ for $24 \mathrm{~h}$, ground and sieved (sieve size 75 micron), named CL-75, and kept in the air tight container. The BG is purchased from Himedia Pvt Ltd.

\section{Instruments and software}

The adsorbent (CL-75) is characterized by the FTIR with the help of Shimadzu FTIR 8400 spectrophotometer. The BET analysis is performed using the nitrogen adsorption-desorption isotherm at degassing temperature of $120^{\circ} \mathrm{C}$. The absorption spectra have been measured by Shimadzu UV-1700 spectrophotometer. Orion 4-star Benchtop pH meter and Orbital shaker of AB-SB systems India have also been used. The physicochemical properties, point of zero charge (pZC) and zeta potential have also been studied following standard procedure [14]. Statistical analyses have been performed by MINITAB 14 software.

\section{Adsorption experiment}

The potentiality of CL-75 as bio-adsorbent has been investigated by selected variable parameters viz. time, dose, concentration and $\mathrm{pH}$. The study has been conducted with the aqueous solution of $\mathrm{BG}$ $(50.0 \mathrm{~mL})$ with varied concentrations $(10.0,20.0,30.0,40.0,50.0,60.0,70.0,80.0,90.0$ and $100.0 \mathrm{mg} / \mathrm{L})$ and CL-75 $(50.0 \mathrm{mg})$ in the batch mode in an orbital shaker $\left(120.0 \mathrm{rpm}\right.$ at $\left.25^{\circ} \mathrm{C}\right)$. Kinetic studies have been performed at 30 and $40{ }^{\circ} \mathrm{C}$, and the different $\mathrm{pH}$ values are adjusted by adding $0.1(\mathrm{~N}) \mathrm{NaOH} / \mathrm{HCl}$ solutions. The concentrations of BG dye are measured from absorbance values at wave length $627.0 \mathrm{~nm}$. The rate of adsorption ( $\mathrm{R} \%$ ) of the dye onto CL-75 is calculated by Eq. (1), and the equilibrium adsorption quantity of CL-75 for dye, $\mathrm{q}_{\mathrm{e}}(\mathrm{mg} / \mathrm{g})$, is calculated by Eq. (2).

$$
\begin{aligned}
& \mathrm{R}(\%)=\frac{\mathrm{C}_{0}-\mathrm{C}_{\mathrm{e}}}{\mathrm{C}_{0}} \times 100 \% \\
& q_{e}=\left(C_{0}-C_{e}\right) \times \frac{V}{W}
\end{aligned}
$$

where $C_{o}$ and $C_{e}$ represent initial and equilibrium concentrations of the dye respectively (mg/L in the liquid-phase, $\mathrm{V}$ is the volume of the experimental solution (1), and $\mathrm{W}$ is the weight ( $\mathrm{g}$ ) of CL-75 used.

\section{Results and discussion}

\section{Characterization of the adsorbent}

The adsorbent material (CL-75) is characterized by FTIR, BET surface area, zeta potential, point of zero charge and physico-chemical properties have been estimated (Table 1). The particle charge demand is negative which means that CL-75 may adsorb positively charged molecules. The $\mathrm{pH}_{\mathrm{PZC}}$ of CL-75 is 6.45 implies that below $\mathrm{pH}_{\mathrm{PZC}}\left(\mathrm{pH}<\mathrm{pH}_{\mathrm{PZC}}\right)$ value, the number of positively charged sites of adsorbent (CL-75) increase and favours anionic dyes to adsorb on the surface. On the other hand, above $\mathrm{pH}_{\mathrm{PZC}}(\mathrm{pH}$ $>\mathrm{pH}_{\mathrm{PZC}}$ ) value, the number of negatively charged sites of adsorbent (CL-75) increase and favours cationic dyes to adsorb. The measured values of BET surface area $\left(\mathrm{S}_{\mathrm{BET}}\right)$, pore volume and pore radius further facilitate the adsorption. The BET surface area $\left(\mathrm{S}_{\mathrm{BET}}\right)$ is low $\left(16.003 \mathrm{~m}^{2} / \mathrm{g}\right)$ and compared with reported values of other bio-adsorbents [15].

The FTIR spectra of the adsorbent (Figures 1(a) and 1(b)), CL-75 have been analysed before and after the dye adsorption. The characteristic peaks at 3400, 2925, 2110, 1648, 1384, 1241, 1097, 1053, $1035,892,762,665$ and $614 \mathrm{~cm}^{-1}$ correspond to various functional groups, such as alcoholic $-\mathrm{OH}$ or amine $-\mathrm{NH}$, alkyl $-\mathrm{CH}$ stretching, alkyne $-\mathrm{C} \equiv \mathrm{C}$, aromatic $-\mathrm{C}=\mathrm{C}$ and aromatic $-\mathrm{CH}$ stretching, mainly $\mathrm{OH}$ and $-\mathrm{NH}$ groups are responsible for binding of BG. Appearance of a new peak at $1544 \mathrm{~cm}^{-1}$ due to N$\mathrm{N}$ stretching frequency may indicate the adsorption of BG on CL-75 and compared with the reported data [16].

The SEM morphologies of CL-75, before and after adsorption are shown in Figures 2(a) and 2(b) respectively. The micrograph of CL-75 exhibits highly porous, irregular, heterogeneous structure with 
fibrous texture [17]. A noticeable change is observed on the surface morphology of CL-75 before and after dye adsorption possibly due to filled up of sites of CL-75 by BG dye and thereby the surface heterogeneity is diminished.

Table 1 Characteristics properties of CL-75.

\begin{tabular}{cc}
\hline Moisture & $10.02 \%$ \\
Bulk density & $0.45 \mathrm{~g} / \mathrm{cm}^{3}$ \\
Ash & $1.2 \%$ \\
Point of zero charge (pzc) & 6.45 \\
Particle charge & $485-510$ millivolt \\
Particle charge demand & $(-) 0.125$ millivolt \\
Total pore volume & $1.516 \times 10^{-02} \mathrm{cc} / \mathrm{g}$ \\
Average pore radius & $18.9479 \AA$ \\
BET surface area & $16.003 \mathrm{~m}^{2} / \mathrm{g}$ \\
\hline
\end{tabular}

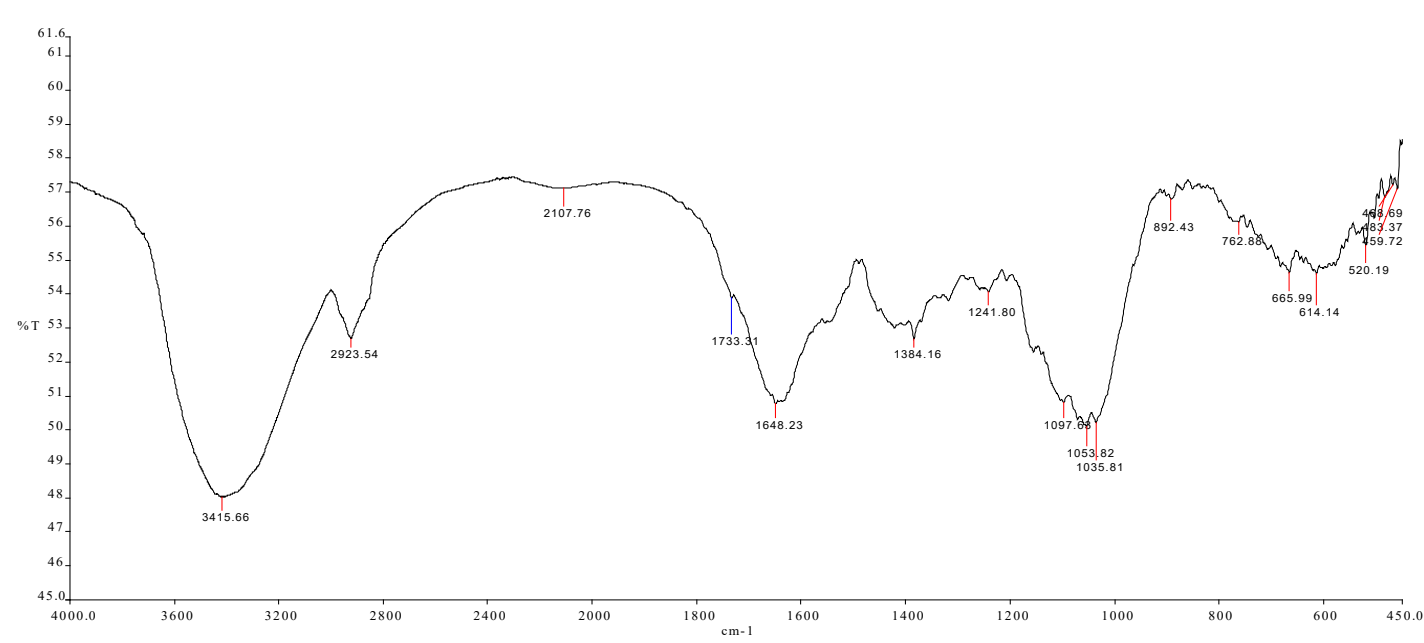

(a)

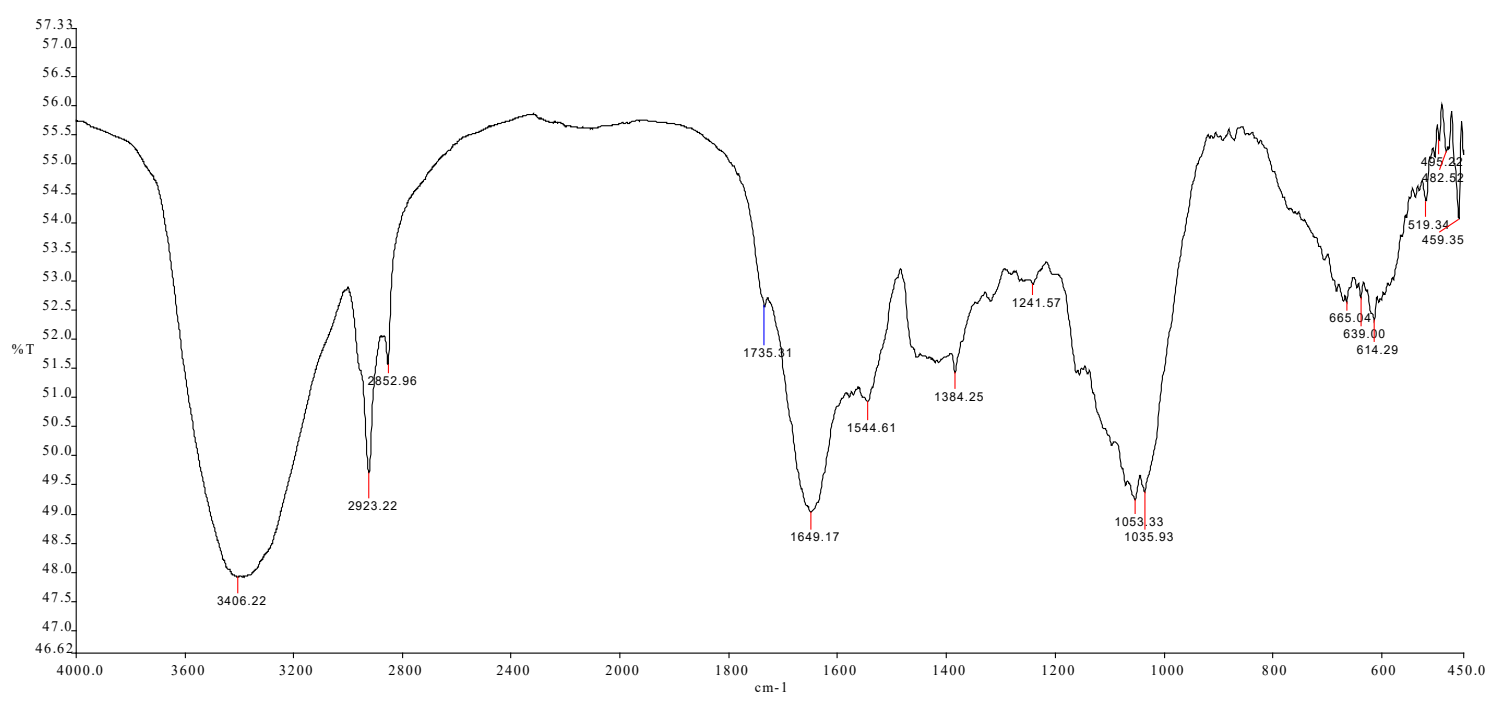

(b)

Figure 1 (a) FTIR spectra of CL-75 before adsorption and (b) FTIR spectra of CL-75 after adsorption. 


\section{Effect of parameters on adsorption \\ Initial concentration}

The rate of adsorption depends on the initial concentration of the adsorbate, which is an important factor for effective adsorption [18]. The removal percentage and adsorption capacity of BG have been investigated in the range of 10.0 to $100.0 \mathrm{mg} / \mathrm{L}$. The uptake capacity also increases steadily from 9.78 to $81.62 \mathrm{mg} / \mathrm{g}$ with an increase in the initial dye concentration due to the transfer of BG to the adsorbent surface by migration at low concentration of dye solution (Figure 3) [19]. As the concentration of BG increases the removal percentage decreases which may be due to the saturation of CL-75 sites or possible repulsive forces between adsorbed layers and remaining bulk molecules. The removal percentage of BG decreases from 97.0 to $83.0 \%$ with the increase of the dye concentration $(10.0-100.0 \mathrm{mg} / \mathrm{L})$.

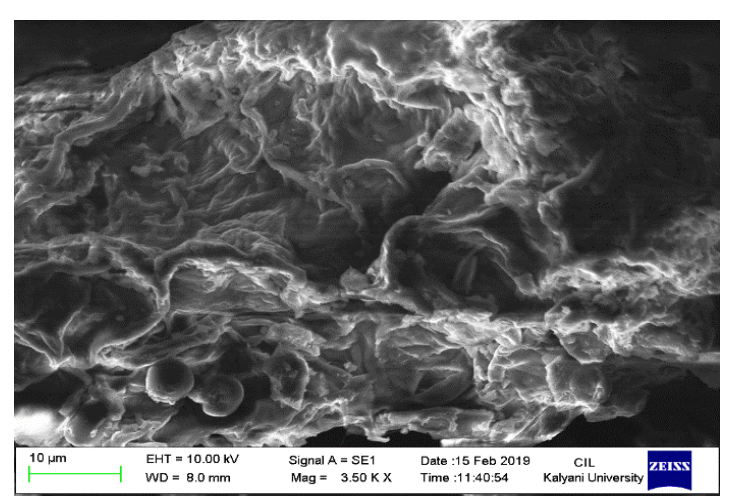

(a)

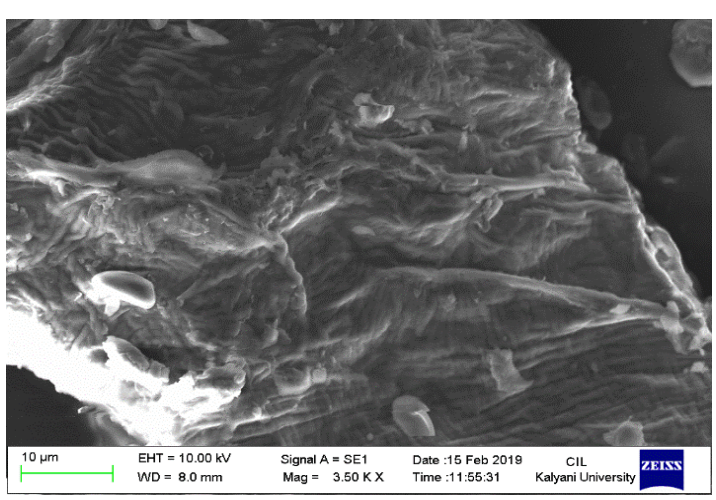

(b)

Figure 2 (a) SEM image of CL-75 before adsorption and (b) SEM image of CL-75 after adsorption.

\section{Contact time}

During adsorption of BG dye $(20.0 \mathrm{mg} / \mathrm{L})$ with CL-75 $(50.0 \mathrm{mg})$, the contact time is varied $(5,10$, 20, 30, 60, 90, 120, 150, 180, 210 and $240 \mathrm{~min}$ ) at room temperature (Figure 4). The plot of \% R vs. time indicates that the removal percentage of BG dye steadily increases (up to $90 \mathrm{~min}$ ) and a smooth and continuous curve pattern is observed probably due to the mono-layer adsorption of BG dye on the surface of CL-75. The adsorption rate is rapid and reaches equilibrium within $120 \mathrm{~min}$. It also signifies that a strong interaction exists between CL-75 and the BG dye in the aqueous environment.

\section{pH}

A series of experiments have been carried out with the $\mathrm{BG}$ dye $(50.0 \mathrm{mg} / \mathrm{L}, \mathrm{pKa}: 4.93$ and 2.62$)$ and CL-75 $(50.0 \mathrm{mg})$. The $\mathrm{pH}$ of the medium is adjusted by adding $0.1(\mathrm{~N}) \mathrm{HCl}$ and $0.1(\mathrm{~N}) \mathrm{NaOH}$ solutions. The adsorption uptake capacity and the removal efficiency increase up to $\mathrm{pH} 7.0$ (Figure 5). The values are found to be $18.38 \mathrm{mg} / \mathrm{g} \& 91.88 \%$ at $\mathrm{pH} 2.0$ and $19.48 \mathrm{mg} / \mathrm{g} \& 97.4 \%$ at $\mathrm{pH} 7.0$ respectively. The average values of uptake capacity and removal efficiency are $19.62 \mathrm{mg} / \mathrm{g} \& 98.1 \%$ respectively in the $\mathrm{pH}$ range 7.0 to 12.0 . In the range of $\mathrm{pH}<\mathrm{pH}_{\mathrm{PZC}}$, the electrostatic interactions are repulsive as positively charged BG molecules repel the positive charged CL-75 and removal percentages are comparatively low. The opposite trend is noticed in the range of $\mathrm{pH}>\mathrm{pH}_{\mathrm{PZC}}$, where the electrostatic interactions are attractive which favours the adsorption between BG molecules and CL-75 [15]. The uptake capacity as well as the removal percentage reaches maximum $(19.78 \mathrm{mg} / \mathrm{g}$ and $98.92 \%)$ at $\mathrm{pH} 12.0$ probably due to strong electrostatic interaction between positively charged BG dye and negatively charged CL-75 [20,21].

\section{Dosages}

In order to optimize the dose of the adsorbent, series of experiments have been performed with varied dosages of CL-75 $(25,50,75,100 \mathrm{mg} ; 50.0 \mathrm{~mL})$ in aqueous solution of BG (50 mg/L) for $2.0 \mathrm{~h}$. The removal percentages vary from 90 to $96 \%(93.43,96.65,90.2$ and $91.32 \%)$ with the variation of dosages. The rate of dye adsorption increases with increasing concentrations of adsorbent and reached a constant value $(50.0 \mathrm{mg}$ ) at equilibrium (Figure 6). At the dose greater than $50 \mathrm{mg}$ of CL-75, the removal percentage of $\mathrm{BG}$ decreases possibly due to a dynamic equilibrium exists between dye molecules present at the surface and at the solution. 


\section{Adsorption kinetic study}

The study of adsorption kinetics provides valuable information on reaction mechanisms. It also predicts the time at which the adsorbate is removed effectively from the solution phase [22]. In this study, three important kinetic models, viz. pseudo-first order, pseudo-second order, Weber and Morris intraparticle diffusion model [23] have been investigated with $B G$ dye $(20.0 \mathrm{mg} / \mathrm{L})$, at different temperatures $\left(30\right.$ and $\left.40{ }^{\circ} \mathrm{C}\right)$ with constant stirring speed $(120.0 \mathrm{rpm})$.

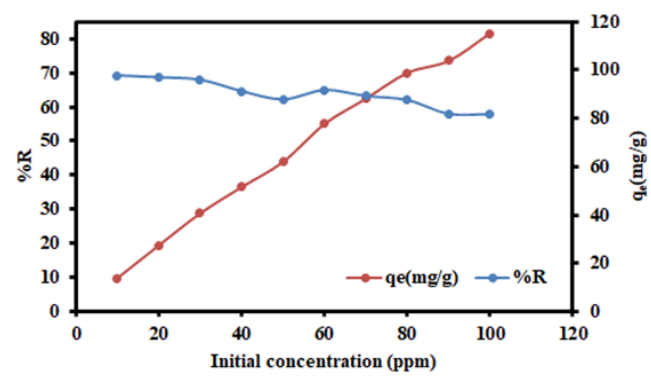

Figure 3 Effect of Initial concentration.

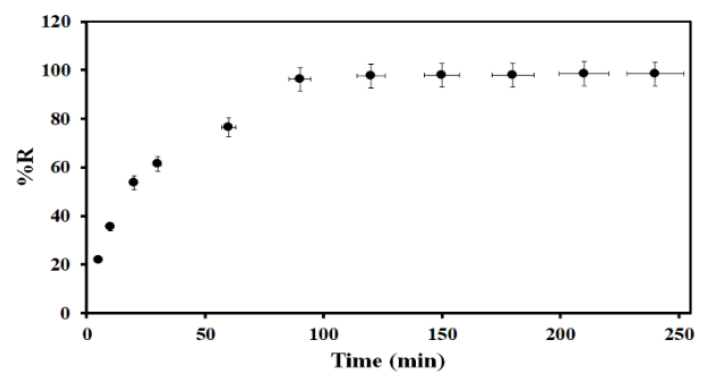

Figure 4 Effect of contact time.

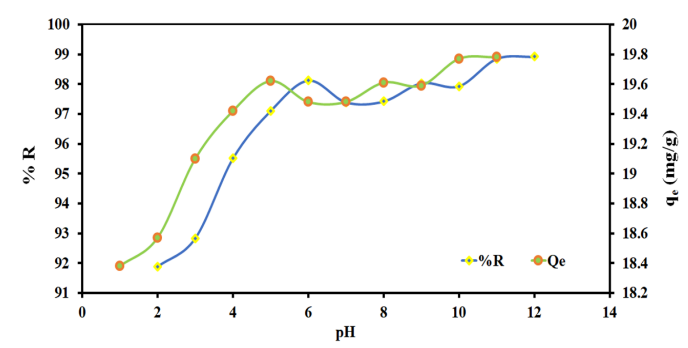

Figure 5 Effect of $\mathrm{pH}$.

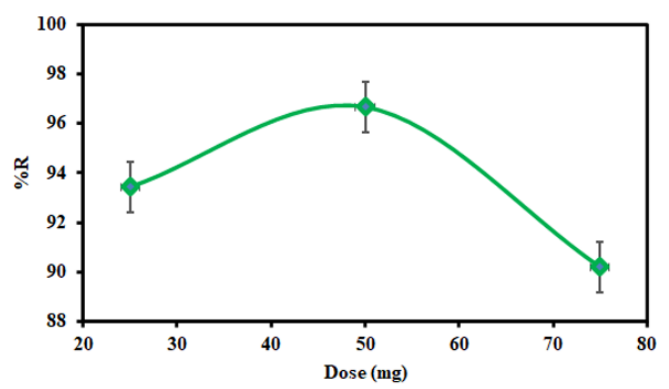

Figure 6 Effect of dosages.

The experiment shows an excellent linearity with high correlation co-efficient values $\left(\mathrm{R}^{2}=0.99\right.$, $0.98)$ in the case of pseudo- $2^{\text {nd }}$ order kinetic model in comparison to pseudo- $1^{\text {st }}$ order $\left(\mathrm{R}^{2}=0.32,0.54\right)$ and intraparticle diffusion $\left(\mathrm{R}^{2}=0.78,0.87\right)$ models. In the case of intraparticle diffusion model, the value 
of diffusion coefficient, $\mathrm{k}_{\mathrm{i}}$, is also calculated (Table 2). It is clear from the plot of $\mathrm{q}_{\mathrm{t}} \mathrm{vs} \mathrm{t}^{0.5}$ that the intraparticle diffusion is involved in the adsorption process but it is not only the rate determining step.

Table 2 Parameters of kinetics studies for adsorption of BG on CL-75.

\begin{tabular}{|c|c|c|c|c|c|c|c|c|c|}
\hline \multirow{2}{*}{$\begin{array}{c}\text { Temp } \\
\left({ }^{\circ} \mathrm{C}\right)\end{array}$} & \multicolumn{4}{|c|}{ Pseudo- $2^{\text {nd }}$ order kinetic } & \multicolumn{3}{|c|}{$\begin{array}{c}\text { Pseudo-1 }{ }^{\text {st }} \text {-order kinetic } \\
\text { model }\end{array}$} & \multicolumn{2}{|c|}{$\begin{array}{c}\text { Intra particle } \\
\text { diffusion model }\end{array}$} \\
\hline & $\mathbf{q}_{\mathrm{e}}$ & $\mathbf{K}_{2}$ & h & $\mathbf{R}^{2}$ & $\mathbf{q}_{\mathrm{e}}$ & $\mathbf{K}_{1}$ & $\mathbf{R}^{2}$ & $\mathbf{k}_{\mathbf{i}}$ & $\mathbf{R}^{2}$ \\
\hline 30 & 19.38 & 0.0417 & 15.67 & 0.99 & 1.47 & 0.0086 & 0.32 & 0.124 & 0.779 \\
\hline 40 & 19.76 & 0.0311 & 12.151 & 0.98 & 2.2 & 0.0094 & 0.54 & 0.091 & 0.868 \\
\hline
\end{tabular}

Note: The initial adsorption rate $(\mathrm{h})$, the equilibrium adsorption capacity $\left(\mathrm{q}_{\mathrm{e}}\right)$ and the $2^{\text {nd }}$ order constants $\left(\mathrm{K}_{2}\right)$ can be determined experimentally (Table 2).

\section{Adsorption isotherm study}

The adsorption isotherm study provides relevant information regarding the interaction of sorbent and liquid phase under equilibrium condition at a certain temperature [16,24]. Several isotherm models are available based on some assumptions. Among various models, Langmuir, Freundlich, DubininRadushkevich (D-R) and Temkin are studied here (Table 3).

The Langmuir isotherm model is based on the assumption that the sorption method takes place on the homogeneous surface, i.e., sorption method is monolayer in nature. The dimensionless separation factor of Langmuir model, $\mathrm{R}_{\mathrm{L}}$, (Eq. (3)) offers important information about the shape of isotherm by interpreting as follows:

$\mathrm{R}_{\mathrm{L}}=1 /\left(1+\mathrm{bC}_{0}\right)$

$\mathrm{R}_{\mathrm{L}}>1.0$ Unfavourable

$\mathrm{R}_{\mathrm{L}}=1.0 \quad$ Linear

$1>\mathrm{R}_{\mathrm{L}}>0$ Favourable

$\mathrm{R}_{\mathrm{L}}=0 \quad$ Irreversible

The Freundlich model provides information about the surface heterogeneity, distribution sites of CL-75 and energy of adsorption. The values of $1 / \mathrm{n}$ mostly predict the state of heterogeneity of surface by ranging between 0 and 1.0. The surface heterogeneity becomes predominating as it tends to 0 [16].

The interaction between the dye molecule and the bio-adsorbent may also be predicted by the Temkin model which is based totally on the assumption that the free energy of sorption is a characteristic feature of the surface coverage. The $\beta$ value in D-R model provides [16] the mean free energy, E $(\mathrm{kJ} / \mathrm{mol})$ of adsorption per molecule of the adsorbate during the transformation from the solid surface from infinity in the bulk of the solution which is expressed as follows:

$\mathrm{E}=1 / \sqrt{ } 2 \beta$

The parameters obtained from four isotherms models by linear fitting are given in the Table 3 . Isotherm plots are given in Figures 7 - 10.

In case of Langmuir and Freundlich models, the relative high values of correlation coefficient satisfactorily explain the adsorption phenomena of BG dye onto CL-75. The maximum adsorption capacity $\left(\mathrm{q}_{\max }\right)$ of BG onto CL-75 is found to be $68.49 \mathrm{mg} / \mathrm{g}$ for the Langmuir model. The degree of adsorption affinity, $b$, indicates a stronger affinity between $B G$ and CL-75. The $R_{L}(0.02)$ value lies between 0 and 1.0 which indicates that the Langmuir isotherm is favourable. In the Freundlich model, the $1 / \mathrm{n}$ value is 0.4562 , which also suggests a stronger adsorption between adsorbate and adsorbent molecules. The lesser the $1 / \mathrm{n}$ value the greater the expected heterogeneity. As the $\mathrm{n}$ value (2.192) is found to lie between 1.0 and 10.0, the sorption process is a favourable one [25]. 
Table 3 Different isotherm models and their parameters for adsorption of BG on CL-75.

\begin{tabular}{ccccc}
\hline Sl. No. & Isotherm Model & Linear form & $\mathbf{R}^{2}$ & Co-efficient \\
\hline 1. & Freundlich & $\log q_{e}=\log K_{F}+\frac{1}{n} \log C_{e}$ & 0.9651 & $\mathrm{n}=2.192, \mathrm{~K}_{\mathrm{F}}=22.7$ \\
2. & Langmuir & $\frac{1}{q_{e}}=\frac{1}{b q_{0} C e}+\frac{1}{q_{0}}$ & 0.9656 & $\mathrm{~b}=0.76, \mathrm{q}_{\max }=68.49$ \\
3. & Dubinin-Radushkevich & $\ln q_{e}=\ln q_{s}-\beta \in^{2}$ & 0.9246 & $\beta=0.0005, \mathrm{q}_{\mathrm{s}}=67.67, \mathrm{E}=31.65$ \\
4. & Temkin & $q_{e}=\frac{R T}{b_{T}} \ln A_{T}+\frac{R T}{b_{T}} \ln C_{e}$ & 0.9202 & $\mathrm{~b}_{\mathrm{T}}=154.83, \mathrm{~A}_{\mathrm{T}}=5.58, \mathrm{~B}=16.002$ \\
\hline
\end{tabular}

Where $C_{e}$ is the equilibrium liquid-phase concentrations of the dye $(\mathrm{mg} / \mathrm{L}), \mathrm{q}_{\mathrm{e}}$ and $\mathrm{q}_{\mathrm{s}}$ are the equilibrium and maximum adsorbed amount of dye on CL-75 respectively $(\mathrm{mg} / \mathrm{g}), \mathrm{b}$ is the Langmuir equilibrium adsorption constant $(\mathrm{L} / \mathrm{mg})$ related to the free energy of adsorption, $\mathrm{K}_{\mathrm{F}}$ is the Freundlich constant $[(\mathrm{mg} / \mathrm{g})(/ \mathrm{mg}) \mathrm{L} / \mathrm{n}]$ related to the strength of the adsorptive bond, and $1 / \mathrm{n}$ is the adsorption intensity factor or surface heterogeneity. In Temkin isotherm model $\mathrm{RT} / \mathrm{b}_{\mathrm{T}}$ corresponds to $\mathrm{B}$ which is related to the heat of adsorption and $\mathrm{T}$ is the temperature $(\mathrm{K}), \mathrm{R}$ is the ideal gas constant $(8.314 \mathrm{~J} / \mathrm{mol} / \mathrm{K})$, and $\mathrm{A}$ is the equilibrium binding constant $(\mathrm{L} / \mathrm{min})$ and $\mathrm{b}_{\mathrm{T}}$ is also a constant. In DubininRadushkevich isotherm model $\mathrm{q}_{\mathrm{s}}$ is named as theoretical saturation capacity ( $\mathrm{mol} / \mathrm{g}$ ), $\beta$ is a constant corresponds to the mean free energy of adsorption per mole of the adsorbate $\left(\mathrm{mol}^{2} / \mathrm{J}^{2}\right), \in$ is the Polanyi potential [23].

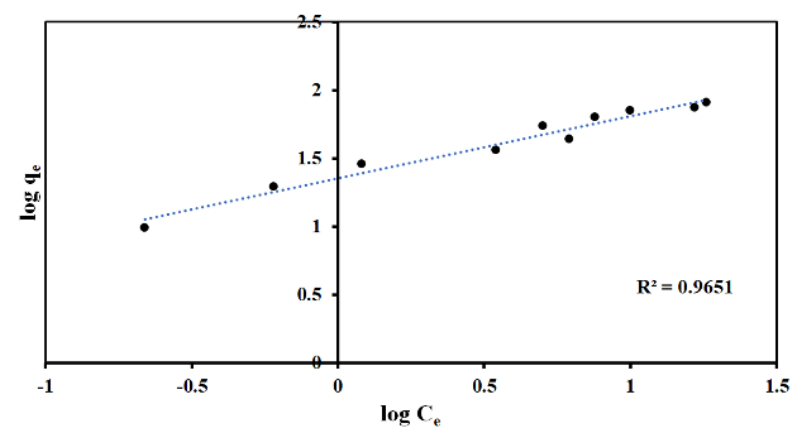

Figure 7 Freundlich isotherm for adsorption of BG dye on CL-75.

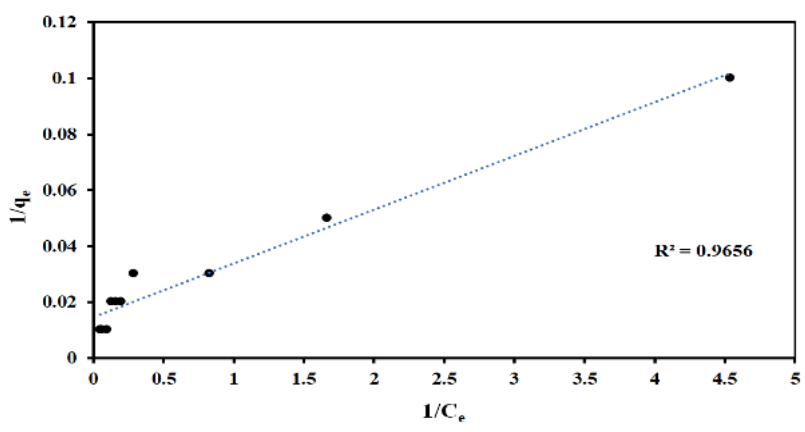

Figure 8 Langmuir isotherm for adsorption of BG dye on CL-75.

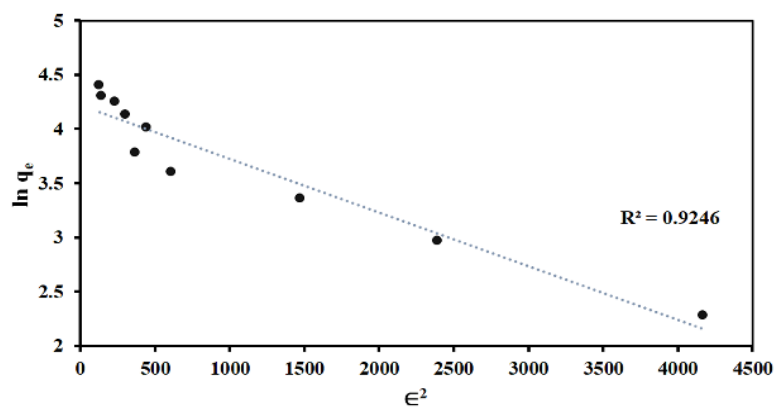

Figure 9 Dubinin-Radushkevich isotherm for adsorption of BG dye on CL-75. 


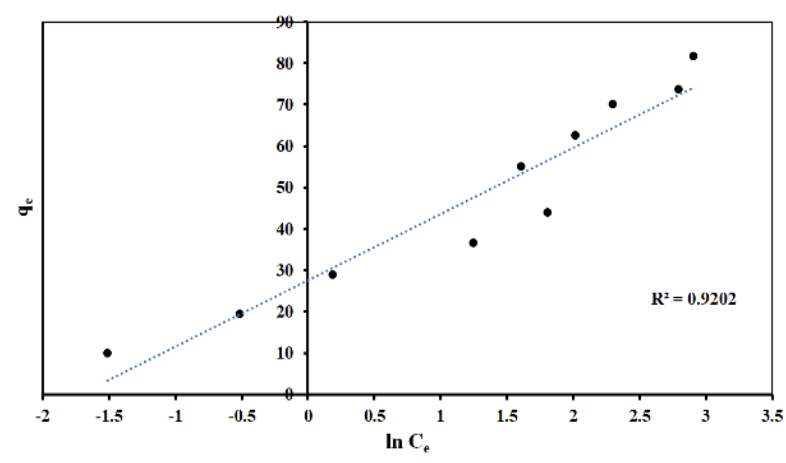

Figure 10 Temkin isotherm for adsorption of BG dye on CL-75.

The Gibb's free energy change is negative. The positive changes in enthalpy and entropy values further supported the spontaneity of the process (Table 4).

Table 4 Thermodynamic parameters for adsorption of BG on CL-75.

\begin{tabular}{cccc}
\hline Temp (K) & $\boldsymbol{\Delta G}(\mathbf{K J} / \mathbf{m o l})$ & $\Delta \mathbf{H}(\mathbf{K J} / \mathbf{m o l})$ & $\Delta \mathbf{S}(\mathbf{K J} / \mathbf{m o l})$ \\
\hline 293 & -82.44 & 20.01 & 0.011 \\
303 & -86.87 & & \\
313 & -97.61 & & \\
\hline
\end{tabular}

\section{Optimization study by Taguchi modelling}

The Taguchi model, an effective tool of Design of Experiment (DOE), conducts series of experiments with minimum resources. In this study, interactions of three parameters (dose, concentration and time) with $\mathrm{q}_{\mathrm{e}}$ are chosen. L9 orthogonal array $(3 \times 3)$ has been applied with nine experiments of three levels and the larger value is better in this experiment (Table 5) [25]. The $\mathrm{S} / \mathrm{N}$ ratio is obtained from the following Eq. (5).

$\mathrm{S} / \mathrm{N}=-10 \log \frac{\sum_{i=1}^{n} \frac{1}{y^{2}}}{n}$

where, $\mathrm{y}_{\mathrm{i}}$ is the estimated value of adsorption capacity and $\mathrm{n}$ is the number of replica of experiments under same conditions.

Table 5 Taguchi L9 orthogonal array design for removal of BG dye in the aqueous medium.

\begin{tabular}{ccccccccc}
\hline $\begin{array}{c}\text { Sl. } \\
\text { No. }\end{array}$ & $\begin{array}{c}\text { Dose } \\
(\mathbf{g m})\end{array}$ & $\begin{array}{c}\text { Conc. } \\
\mathbf{( p p m )}\end{array}$ & $\begin{array}{c}\text { Time } \\
(\mathbf{m i n})\end{array}$ & $\begin{array}{c}\text { Dose } \\
\mathbf{( g m )}\end{array}$ & $\begin{array}{c}\text { Conc. } \\
(\mathbf{p p m})\end{array}$ & $\begin{array}{c}\text { Time } \\
(\mathbf{m i n})\end{array}$ & $\mathbf{q} \mathbf{( \mathbf { m g } / \mathbf { g } )}$ & S/N ratio \\
\hline 1 & 0.05 & 25.0 & 30.0 & 1 & 1 & 1 & 20.19 & 26.102 \\
2 & 0.05 & 50.0 & 60.0 & 1 & 2 & 2 & 46.25 & 33.30 \\
3 & 0.05 & 75.0 & 120.0 & 1 & 3 & 3 & 71.95 & 37.141 \\
4 & 0.01 & 25.0 & 60.0 & 2 & 1 & 2 & 104.9 & 40.416 \\
5 & 0.01 & 50.0 & 120.0 & 2 & 2 & 3 & 130.35 & 47.248 \\
6 & 0.01 & 75.0 & 30.0 & 2 & 3 & 1 & 92.95 & 39.365 \\
7 & 0.1 & 25.0 & 120.0 & 3 & 1 & 3 & 11.845 & 21.471 \\
8 & 0.1 & 50.0 & 30.0 & 3 & 2 & 1 & 22.5 & 27.044 \\
9 & 0.1 & 75.0 & 60.0 & 3 & 3 & 2 & 33.385 & 30.471 \\
\hline
\end{tabular}

Where, dose of CL-75, conc. of BG dye and time of contact are considered. 
It is revealed that adsorption capacities of BG dye vary from 11.845 to $130.35 \mathrm{mg} / \mathrm{g}$ obtained by combination of several factors.

Table 6 Response table for signal to noise ratio.

\begin{tabular}{cccc}
\hline Level & Dose & Concentration & Time \\
\hline 1 & 42.34 & 29.33 & 30.84 \\
2 & 32.18 & 35.86 & 34.76 \\
3 & 26.33 & 35.66 & 35.29 \\
Delta & 16.01 & 6.53 & 4.45 \\
Rank & 1 & 2 & 3 \\
\hline
\end{tabular}

Table 7 Response table for means.

\begin{tabular}{cccc}
\hline Level & Dose & Concentration & Time \\
\hline 1 & 142.73 & 45.65 & 45.21 \\
2 & 46.13 & 99.70 & 61.51 \\
3 & 22.58 & 66.10 & 104.71 \\
Delta & 120.16 & 54.06 & 59.5 \\
Rank & 1 & 3 & 2 \\
\hline
\end{tabular}

It is clear from the main effect plot (Table 7) that $\mathrm{q}_{\mathrm{e}}$ value decreases with increasing dose and increases with increasing time. Initially it increases with concentration in the range 25.0 to $50.0 \mathrm{ppm}$ and then decreases. The $\mathrm{S} / \mathrm{N}$ ratio plot for each level of several factors indicate that the maximum variation takes place with the dose of CL-75 followed by concentration and time. In this perspective, dose has the most significant effect for highest adsorption capacity (Table 6).

Ranking of parameters based on $\mathrm{S} / \mathrm{N}$ ratio is Dose $>$ Concentration $>$ Time means that dose affects $\mathrm{q}_{\mathrm{e}}$ at highest level and time at lowest level (Table 6). The role of various parameters indicates that interactions between dose, concentration and time ranges from $0.05-0.1 \mathrm{~g}, 25.0-50.0 \mathrm{mg} / \mathrm{L}$ and 30.0 $60.0 \mathrm{~min}$ are best possible ranges of parameters for experimental studies.

The ANOVA analysis has been performed to predict the statistical significance of variable parameters. During this analysis, the greater value of $F$ ratio indicates major contribution of the variable or factor. ANOVA results (Table 8) reveal that dose has the higher influence on the uptake of dye followed by time and concentration. Hence, the order of several factors is Dose $>$ Time $>$ Concentration.

Table 8 Analysis of Variance for $\mathrm{q}_{\mathrm{e}}$ on BG dye.

\begin{tabular}{cccccc}
\hline Source & DF & MS & SS & F & p \\
\hline Concentration & 2 & 4469 & 2235 & 0.41 & 0.683 \\
Time & 2 & 5673 & 2836 & 0.53 & 0.611 \\
Dose & 2 & 24325 & 12162 & 5.55 & 0.043 \\
\hline
\end{tabular}

Note: DF is degree of freedom, MS is mean square, $\mathrm{SS}$ is sum of square and F is F-ratio.

\section{Conclusions}

In the present work, the biomass derived from coriander leaf has been investigated as a potential adsorbent for the removal of brilliant green dye in the aqueous environment. The effects of $\mathrm{pH}$, dose, concentration of dye and time of contact have been investigated. The uptake capacities and the removal percentages are found to be maximum at $\mathrm{pH}>\mathrm{pH}_{\mathrm{PZC}}$ due to strong electrostatic interaction. The adsorption process follows Freundlich and Langmuir isotherms $\left(\mathrm{q}_{\max }-68.49 \mathrm{mg} / \mathrm{g}\right)$ and fit with pseudo$2^{\text {nd }}$ order kinetic model based on higher regression value. The Gibb's free energy change is negative which also favours the spontaneity of the process. The Freundlich constant, n, suggests a strong interaction between the dye and the adsorbent. Taguchi experimental design with L9 orthogonal array has been studied for the interaction of parameters (dose, concentration and time) during the removal of dye in 
the batch mode considering the highest adsorption uptake capacity. Among three factors, dose has the highest influence on the uptake of dye followed by time and concentration, and further supported by the ANOVA analysis (Dose $>$ Time $>$ Concentration). Thus, the adsorbent derived from the coriander leaf might be helpful for the sequestration of Brilliant green dye from real samples as well as industrial effluents.

\section{Acknowledgements}

We gratefully acknowledge DST-PURSE, New Delhi and University of Kalyani, India, for providing infrastructural facilities. We are also thankful to Indian Association for Cultivation of Science, Kolkata for BET analysis.

\section{References}

[1] G Mckay, JF Porter and GR Prasad. The removal of dye colours from aqueous solutions by adsorption on low-cost materials. Water Air Soil Pollut. 1999; 114, 423-38.

[2] A Bhatnagar and AK Minocha. Assessment of the biosorption characteristics of lychee (Litchi chiesas) peel waste for the removal of Acid Blue 25 dye from water. Environ. Technol. 2010; 31, 97-105.

[3] R Sivashankar, AB Sathya, K Vasantharaj and V Sivasubramanian. Magnetic composite an environmental super adsorbent for dye sequestration - A review. Environ. Nanotechnol. Monit. Manag. 2014; 1-2, 36-49.

[4] VK Gupta and Suhas. Application of low-cost adsorbents for dye removal - a review. J. Environ. Manag. 2009; 90, 2313-42.

[5] KAR Rao and MK Uddin. Adsorption properties of coriander seed powder (Coriandrum sativum): Extraction and pre-concentration of $\mathrm{Pb}$ (II), $\mathrm{Cu}$ (II) and $\mathrm{Zn}$ (II) ions from aqueous solution. Adsorp. Sci. Technol. 2010; 30, 127-46.

[6] S Agarwal, VK Gupta, M Ghasemi and J Azimi-Amin. Peganum harmala-L seeds adsorbent for the rapid removal of noxious brilliant green dyes from aqueous phase. J. Mol. Liq. 2017; 231, 296-305.

[7] VK Gupta, PJM Carrott, MMLR Carrott and Suhas. Low-cost adsorbents: Growing approach to wastewater treatment - a review. Crit. Rev. Environ. Sci. Technol. 2009; 39, 783-842.

[8] A Srinivasan and T Viraraghavan. Decolorization of dye wastewaters by biosorbents: A review. $J$. Environ. Manag. 2010; 91, 1915-29.

[9] LP Nimish, BK Sanjay, MB Nayna and DR Jaimik. Phytopharmacological properties of Coriander Sativum as a potential medicinal tree: An overview. J. Appl. Pharm. Sci. 2011; 1, 20-5.

[10] M Nadeem, FM Anjum, MI Khan, S Tehseen, A El-Ghorab and JI Sultan. Nutritional and medicinal aspects of coriander (Coriandrum sativum L.): A review. Br. Food J. 2013; 115, 743-55.

[11] D Karunasagar, MVB Krishna, SV Rao and J Arunachalam. Removal and preconcentration of inorganic and methyl mercury from aqueous media using a sorbent prepared from the plant Coriandrum sativum. J. Hazard. Mater. 2005; 118, 133-9.

[12] RAK Rao and M Kashifuddin. Adsorption properties of coriander seed powder (Coriandrum sativum): Extraction and pre-concentration of $\mathrm{Pb}$ (II), $\mathrm{Cu}$ (II) and $\mathrm{Zn}$ (II) ions from aqueous solution. Adsorp. Sci. Technol. 2012; 30, 127-46.

[13] R Yahya, SN Taqui, A Hassan, F Khanum and AA Syed. Valorization of nutraceutical industrial coriander seed spent by the process of sustainable adsorption system of acid black 52 from aqueous solution. Int. J. Environ. Res. 2019; 13, 639-59.

[14] BK Nandi, A Goswami and MK Purkait. Adsorption characteristics of brilliant green dye on Kaoli. J. Hazard. Mater. 2009; 161, 387-95.

[15] A Ghazali, M Shirani, A Semnani, V Zare-Shahabadi and M Nekoeinia. Optimization of crystal violet adsorption onto Date palm leaves as a potent biosorbent from aqueous solutions using response surface methodology and ant colony. J. Environ. Chem. Eng. 2018; 6, 3942-50.

[16] SN Taqui, R Yahya, A Hassan, F Khanum and AA Syed. Valorization of nutraceutical industrial coriander seed spent by the process of sustainable adsorption system of Acid Black 52 from aqueous solution. Int. J. Environ. Res. 2019; 13, 639-59.

[17] NK Mondal, A Samanta, S Chakraborty and WA Shaikh. Enhanced chromium (VI) removal using banana peel dust: Isotherms, kinetics and thermodynamics study. Sust. Water Resour. Manage. 2018; 4, 489-97.

[18] Z Rawajfiha and N Nsour. Thermodynamic analysis of sorption isotherms of chromium (VI) anionic species on reed biomass. J. Chem. Thermodyn. 2008; 40, 846-51. 
[19] V Katheresan, J Kansedo and SY Lau. Efficiency of various recent wastewater dye removal methods: A review. J. Environ. Chem. Eng. 2018; 6, 4676-97.

[20] A Kausar, M Iqbal, A Javeda, K Aftaba, ZH Nazli, HN Bhatti and S Nouren. Dyes adsorption using clay and modified clay: A review. J. Mol. Liq. 2018; 256, 395-407.

[21] MA Salem, RG Elsharkawy and MF Hablas. Adsorption of brilliant green dye by polyaniline/silver nanocomposite: Kinetic, equilibrium, and thermodynamic studies. Eur. Polym. J. 2016; 75, 577-90.

[22] KV Kumar and S Sivanesan. Prediction of optimum sorption isotherm: Comparison of linear and non-linear method. J. Hazard. Mater. 2005; 126, 198-201.

[23] F Haghseresht and GQ Lu. Adsorption characteristics of phenolic compounds onto coal-rejectderived adsorbents. Energy Fuels 1998; 12, 1100-7.

[24] N Ayawei, AN Ebelegi and D Wankasi. Modelling and interpretation of adsorption isotherms. $J$. Chem. 2017; 2017, 3039817.

[25] HY Yen and CP Lin. Adsorption of Cd (II) from wastewater using spent coffee grounds by Taguchi optimization. Desalin. Water Treat. 2015; 57, 11154-61. 